\title{
Wittgenstein on the Structure of the Soul: a New Interpretation of Tractatus 5.5421
}

\section{Gert-Jan C. Lokhorst, Erasmus University}

What is the most obscure remark in Wittgenstein's Tractatus? ${ }^{1}$ We have an embarras de choix, but TLP 5.5421 may well lay claim to this epithet. In this passage, Wittgenstein tells us which implications his analysis of propositional attitude ascriptions in TLP 5.542 has for our views on the 'soul' ('mind') or 'subject':

5.542 It is clear, however, that 'A believes that p', 'A thinks $p$ ', 'A says $p$ ' are of the form ' " $p$ " says $p$ ': and this does not involve a correlation of a fact with an object, but rather the correlation of facts by means of the correlation of their objects.

5.5421 This shows too that the soul ${ }^{2}$ - the subject, etc. - as it is conceived in the superficial psychology of the present day is a monstrosity.

For a composite soul would no longer be a soul.

At least four conflicting interpretations have been given of TLP 5.5421:

(1) Some commentators claim that it shows that Wittgenstein regarded the mind as a complex entity: it is a Humean "bundle or collection' of thoughts. ${ }^{3}$ Perszyk calls this interpretation the 'standard reading' of the passage. ${ }^{4}$

1. L.J.J. Wittgenstein, Logisch-philosophische Abhandlung: Kritische Edition, ed. by B.F. McGuinness and J. Schulte. Frankfurt am Main, Suhrkamp, 1989. Henceforth referred to as 'TLP'.

2. Wittgenstein uses the word 'Seele'. As S. A. Kripke notes in his Wittgenstein on Rules and Private Language, Cambridge, Mass., Harvard University Press, 1982, pp. 49 and 127, 'mind' is often a better translation of this word than 'soul' because it has less religious and philosophical connotations. Since most readers of the English version of the Tractatus will be accustomed to the translation 'soul', we will use the latter term.

3. For example, J. Hintikka, 'On Wittgenstein's "Solipsism" ', Mind 67 (1958), 8891, and M. Black, A Companion to Wittgenstein's 'Tractatus', Ithaca, N.Y., Cornell U.P., 1964, p. 301.

4. K.J. Perszyk, 'Tractatus 5.54-5.5422', Philosophia 17 (1987), 111-126, quotation from p. 117. 
(2) According to others, Wittgenstein precisely rejected this view: according to them, he wanted to say that the mind is simple.

(3) Some commentators want to have it both ways. For example, Hacker enigmatically writes: 'The claim should be interpreted thus: the soul conceived of as a unitary simple subject does not exist. But conceived of as a manifold, it is the legitimate subject-matter of psychology'. 6

(4) Sluga, on the other hand, thinks that Wittgenstein wanted to show that the soul is neither complex nor simple. He credits him with 'the discovery that the notion of the soul or subject is altogether incoherent and that, consequently, there cannot be any such thing'?

Kripke keeps an open mind: 'the obscure passage Tractatus 5.5421 . . . does not appear to be directed primarily at Hume's theory'. ${ }^{8}$ Some commentators see no solution at all: Urmson speaks of 'almost impenetrable obscurity'. ${ }^{9}$ Others see no problem at all: 'All this is commonplace and evident', Rosenberg remarks after quoting the relevant passages. ${ }^{10}$

The great variety of existing interpretations suggests that the key to TLP 5.5421 has hitherto not been found. After having thought about the passage for many years, we believe that we have finally stumbled across a solution. We think that our interpretation is the first one which really does justice to the passage, in the sense of reconstructing it as a clear and cogent argument. Moreover, it has all other virtues any good interpretation of the passage should have: it is in accord with the textual evidence, it does not make implausible assumptions about Wittgenstein's knowledge of 'the psychology of the present day', it does not treat the passage as just an isolated remark, and it suggests what the historical and systematical sources of his view may have been. Finally, our interpretation shows that the passage is more important than previous commentators have thought: it turns out to be closely 5. G.E.M. Anscombe, An Introduction to Wittgenstein's Tractatus, 4th ed., London, Hutchinson, 1971, p. 88. J. Hintikka and B. Wolniewicz, personal communications, 1989.

6. P.M.S. Hacker, Insight and Illusion, 2nd ed., Oxford, Clarendon Press, 1986, p. 62 .

7. H. Sluga, 'Subjectivity in the Tractatus', Synthese 56 (1983), 123-139, quotation from pp. 129-130.

8. Kripke, op. cit., p. 131.

9. J.O. Urmson, Philosophical Analysis, Oxford, Blackwell, 1956, p. 133.

10. J. Rosenberg, 'Intentionality and Self in the Tractatus', Noûs 2 (1969), 341-358, quotation from p. 342 . 
connected with the remarks on the perspectival character of the 'metaphysical subject' in TLP $6.631 \mathrm{ff}$.

All this does not imply, however, that our interpretation of TLP 5.5421 is a justification of it. We think that it is an unfortunate remark, which is false (or misleading at best) and should never have made its way into the Tractatus.

\section{Thoughts}

As TLP 5.5421 is presented as a corollary of TLP 5.542 we have to understand the latter passage first. Fortunately, this is not too difficult.

Wittgenstein begins by saying that 'A thinks p' is of the same form as " " $p$ " says p'. What is the form of " $p$ " says $p$ "? Well, it is an ascription of a fact to a sentence: it says that the sentence ' $p$ ' is a picture of the fact that $p$. If 'A thinks $p$ ' is to be similar to " $p$ " says $\mathrm{p}$ ', it should also say that some sentence is a picture of the fact that p. It does so if we analyse it as saying that one of A's thoughts is a picture of the fact that $\mathrm{p}$. We know that Wittgenstein considered thoughts as similar to sentences; they consist of 'psychical constituents that have the same sort of relation to reality as words'. ${ }^{11}$ So 'A thinks $p$ ' is in its analysed form indeed analogous to " "p" says p': both involve the ascription of a fact to a sentence-like picture.

After remarking that 'A thinks $\mathrm{p}$ ' is of the same form as " " $\mathrm{p}$ " says $\mathrm{p}$ ', Wittgenstein says that both sentences involve a 'correlation of facts by means of the correlation of their objects'. This remark may be understood if we consider how a picture represents a fact. It is capable of doing so because it is a fact itself; it is the fact that certain pictorial elements are arranged in a certain way. Each pictorial element denotes a corresponding object. The fact that the pictorial elements are arranged in such-and-such a way says that another fact is the case, namely that the objects which correspond to the elements are arranged in the same way. So when a thought represents a fact, we have 'a correlation of facts' (namely the thought on the one hand, and the fact which is pictured by the thought on the other

11. Letter to Russell dated 19.8.19, reprinted in L.J.J. Wittgenstein, Notebooks 1914-1916, edited by G.H. von Wright and G.E.M. Anscombe, 2nd ed., Oxford, Blackwell, 1979, p. 131. 
hand) 'by means of a correlation of their objects' (namely the 'psychical constituents' of the thought on the one hand and the objects of the pictured fact on the other hand), which is precisely what TLP 5.542 asserts.

It is important to notice that pictures (including thoughts) are always complex: the fact that certain elements are arranged in a certain way necessarily involves at least two elements. We may call the number of components of a fact its 'logical complexity' (TLP 4.04). A picture and the fact which it represents have the same 'logical complexity' (TLP 4.04), for there are no 'multi-purpose' pictorial elements denoting several objects or 'empty' pictorial elements which do not denote an object. This explains why a thought-ascription 'does not involve a correlation of a fact with an object': an object is simple and does not have the 'logical complexity' which is required to represent a fact.

The above is hardly controversial. Dozens of commentators have offered similar anlyses in the past three decades. The only peculiar feature of our interpretation is that we want to read TLP 5.542 as a proposal for a semantical analysis of thought-ascriptions. One should not say that 'A thinks $\mathrm{p}$ ' is equivalent to 'one of A's thoughts says p'. For if we did so, thought-ascriptions would become nonsensical. In the ideal language Wittgenstein had in mind, it cannot be expressed that a certain picture represents a certain fact; any attempt to do so would result in metalinguistic nonsense. ' " $\mathrm{p}$ " says p' is a good example of such nonsense: it tries to say what can only be shown. It is a correct expression in the ladder-language in which the Tractatus is written, but it cannot belong to the objectlanguage. However, there seems to be no good reason to exclude thought-ascriptions from language. Therefore, 'A thinks p' should not be regarded as being equivalent to any sentence of the form " " $p$ " says p', 'thought $T$ says $p$ ' or suchlike. Rather, it says that one of A's thoughts says that $p$; it is true iff one of A's thoughts says that $p$. In this way thought-ascriptions remain ordinary sentences of language. An additional attractive feature of a semantical analysis is that it may easily be transformed into a truth-functional analysis. ${ }^{12}$

12. G.J.C. Lokhorst, 'Ontology, Semantics and Philosophy of Mind in Wittgenstein's Tractatus: a Formal Reconstruction', Erkenntnis 29 (1988), 35-75, and 'Truthfunctionality and Supervenience in the Tractatus', in P. Weingartner and G. Schurz, eds., Reports of the 13th International Wittgenstein-Symposium, Vienna, HölderPitchler-Tempsky, 1989, 276-278. 


\section{The empirical self}

How does the above account apply to TLP 5.5421? Let us begin by considering the first interpretation on the list presented above: the view that Wittgenstein considered the soul or subject as being identical with a Humean bundle or collection of thoughts.

We may call such a bundle of thoughts the 'empirical self'. This is the self which may be studied by psychology (TLP 5.641), and its identification with a bundle of thoughts explains why it may indeed be studied empirically. There even are two ways in which psychology may study the empirical self. First, thoughts are facts in the world. They may therefore be investigated in the same way as other facts in the world are studied. And secondly, thoughts may be studied by means of what they represent, that is, by way of their contents. The latter approach would presumably be the method of introspective (or at any rate 'phenomenalistic') psychology.

There is no way to bridge the gap between the results of both methodologies. Psychology can never discover whether a given thought represents a given fact, for a thought can only show what it represents, and any sentence that says that this thought represents a certain fact can only be metalinguistic nonsense which does not belong to language. Psychophysical laws in the sense of senseascribing laws are as impossible to formulate as semantical laws are.

\section{The simplicity of the soul (subject)}

According to the adherents of the first standpoint on our list, the soul or subject which is mentioned in TLP 5.5421 is identical with the empirical self which we have defined above. However, there are at least two reasons why this interpretation cannot be correct.

In the first place, Wittgenstein emphatically says that 'a composite soul would no longer be a soul'. The empirical self, however, is complex. It is even doubly complex: it is complex because it is a bundle of several thoughts, and it is complex because each thought is complex in itself. Therefore the soul cannot be identical with the empirical self.

There is only one way to counter this objection. One might maintain that Wittgenstein does not say that he himself regards the 
soul as complex; he merely ascribes this view to the superficial psychologists of his time. Thus, TLP 5.5421 should be read as 'A composite soul would no longer be a soul according to the superficial psychologists of the present day'. However, this suggestion does too much violence to the text. The text certainly gives the impression that Wittgenstein proclaims the just-mentioned view as his own standpoint.

In the second place, this interpretation charges Wittgenstein with having a caricatural view of the psychology of his time. There were almost no psychologists in his time who considered the soul, mind or subject as simple. The view that it is a bundle of thoughts was the most popular view in psychology around the turn of the century. We cannot give a full survey of the literature here, but only refer to Weininger's Geschlecht und Charakcter, a book which Wittgenstein read and admired highly. Weininger heaped abuse on the psychologists of his time precisely because they regarded the soul as being nothing but a bundle of thoughts. He argued that this view is fine as far as women are concerned, but patently false when one takes male Caucasian geniuses into account. ${ }^{13}$ It is quite possible that Wittgenstein got his conception of the psychology of his time from Weininger; there are more traces of his influence. ${ }^{14}$

In sum, we seem to be obliged to accept the second interpretation on our list: the subject or soul is simple. Although it is simple, 'the I is no object' (Notebooks 7.8.16): for it 'does not exist' (TLP 5.631) and 'does not belong to the world (TLP 5.632). We will return to a discussion of its nature below.

The above interpretation is not only in accord with what the last sentence of TLP 5.5421 literally says, it is also in accord with the Schopenhauerian remarks in TLP 5.64 about the shrinking of the subject into a point without extension.

\section{How Wittgenstein changed his mind}

Wittgenstein radically changed his mind on the issue of the complexity of the subject between the time he dictated his notes to 13. O. Weininger, Geschlecht und Charakter: Eine prinzipielle Untersuchung, Vienna and Leipzig, Braumüller, 1926, Part II, Chaps. 6-9.

14. See, e.g. Sluga, op. cit. The remark in TLP 5.1362 that " "A knows that $p$ is the case" is senseless when $p$ is a tautology' may also be an echo from Weininger. He wrote that a tautology does not express knowledge and cannot be the object of an act of thought. (Ibid., Part II, Ch. 7). 
Moore (1914) and the time he wrote the final version of the Tractatus (1918). The last sentence of the notes dictated to Moore says: "The relation of "I believe $p$ " to " $p$ " can be compared to the relation of " $\mathrm{p}$ " says (besagt) p' to p: it is just as impossible that $I$ should be a simple as that " $p$ " should be'. ${ }^{15}$

Here Wittgenstein still adhered to the view that the subject is a complex entity similar to the empirical self we mentioned above. However, it is obvious that he says just the opposite in TLP 5.5421. He probably changed his mind as a result of reading Schopenhauer, who wrote in Die Welt als Wille und Vorstellung that the self is 'an indivisible point' which is the 'centre of all existence'. (The influence of Schopenhauer is very conspicuous in the Notebooks.) Confusing TLP 5.5421 with the just-mentioned remark in the notes dictated to Moore is one of the main causes of the 'standard' misinterpretation of TLP 5.5421.

\section{The soul (subject) does not represent}

We have reached the conclusion that the soul or subject is simple. However, as we have already seen in our list of previous commentaries, Sluga claimed that the Tractarian soul cannot be simple. To quote him in full:

He [i.e., Wittgenstein] raises a crucial difficulty for all those who argue that only a simple substance can have mental attributes. If among those attributes is the ability to have representations and if representations of complexes are, by nature, themselves complex, we must ask how a simple substance is capable of having complex representations.

But that suggestion, combined with the claim that a composite soul is not a soul any longer, seems to lead to the discovery that the notion of the subject is altogether incoherent and that, consequently, there cannot be any such thing. ${ }^{16}$

How do we reply to Sluga's analysis?

Sluga certainly draws attention to an important point. As he makes clear, Wittgenstein's account of representation is, for example, obviously incompatible with Leibniz's theory of simple monads which are 'mirrors of the world'. According to the picture

15. Notebooks, op. cit., p. 119.

16. Sluga, op. cit., pp. 129-130. 
theory there can be no simple monads which represent complex facts. The Many cannot be represented by the One.

However, a similar critique does not apply to Wittgenstein's own view of the soul as a simple entity. For he never says that the soul represents. Indeed, it is just the other way around: we want to suggest that TLP 5.5421 may most naturally be read as a straightforward rejection of the view that the soul represents.

When we adopt this suggestion, the line of argument in TLP 5.542-5.5421 suddenly becomes crystal-clear. Wittgenstein begins by noting that anything which represents a fact must be complex. From this he draws two conclusions. First, that Russell's and Moore's conception of the soul as an (indivisible) object is false. And secondly, that the conception of the psychologists of his time is wrong. For these regard the soul as something which represents (or as a collection of representations). But that implies that it is complex, and that is absurd, for 'a composite soul would no longer be soul'. Therefore the psychologists are wrong in saying that the soul represents.

This, then, is our new analysis of TLP 5.5421: it is a reductio ad absurdum of the view that the soul or subject is a representational entity. The soul is no 'mirror of nature'; rather, it is a windowless Leibnizian monad which differs from a true Leibnizian monad in that it does not represent anything. The soul may perhaps in some way be related to thoughts which represent facts (although it is not clear how we could conceive of such a relation), but it does not represent facts itself.

Besides reconstructing TLP 5.5421 as a clear and cogent argument, our interpretation has at least two other advantages over the 'standard' interpretation.

First, it does not imply that Wittgenstein had a superficial knowledge of the psychology of his times. It is undoubtedly correct to suppose that most psychologists thought that the mind has a representational character. Indeed, most psychologists still think so today.

Secondly, our interpretation fits in very nicely with TLP 5.631. This passage may even be regarded as the clincher for our analysis, for here Wittgenstein unequivocally reaffirms the conclusion we have just ascribed to him: 'There is no such thing as the thinking, representing subject'. Even if there were a subject, it could not think or represent, for then it would be complex. In the same 
passage, Wittgenstein goes on to assert that in an important way there is no subject' at all. This statement also supports our thesis that the Tractarian subject does not represent: for it would be hard to imagine how something that does not exist could represent anything.

Thus, even if our suggestion may seem strange at first, there really is no way to avoid it!

\section{The idleness of the soul (subject)}

The soul or subject as it is portrayed by Wittgenstein is a pretty useless entity. It does not represent itself and cannot represent any other fact either. Nor does it play any role in the attribution of propositional attitudes: 'A thinks that $p$ ' is true iff some of the facts (thoughts) constituting the person A represent the fact that $\mathrm{p}$. The soul does not come in anywhere. Moreover, the Humean argument in $5.631 \mathrm{ff}$. is designed to show that the soul cannot be represented by any other instance either. Thus, it seems to play no role in representation whatsoever.

Some commentators deny this: they argue that the soul is the necessary precondition for representation. According to them, it is the instance which confers meanings on symbols. Pictures, thoughts and sentences would be senseless, lifeless facts in the world if the metaphysical subject did not provide pictorial elements with denotations. ${ }^{17}$

However, this suggestion is not tenable. In the first place, it is utterly incomprehensible. It is inconceivable how a metaphysical, non-wordly instance could ever imbue facts in the world with worldly meanings. It should at least partly 'reach out' to the facts ('stick its fingers into the world') in order to do this. Moreover, it cannot be simple if it is to do this. It should have some internal structure corresponding to the structures of the facts which it is relating to each other, for it would not be able to distinguish between different facts otherwise.

In the second place, not the slightest evidence for the suggestion can be found in the Tractatus. Wittgenstein discusses only interpreted

17. See, for example, A. Kenny, 'Wittgenstein's Early Philosophy of Mind', in I. Block, ed., Perspectives on the Philosophy of Wittgenstein, Oxford, Blackwell, 1981, 140-147. 
symbols. The interpretation is always considered as given beforehand. 'The pictorial relation which turns a fact into a picture belongs to the picture itself.' (TLP 2.1513) It is not necessary to invoke a soul as a deus ex machina which has to give meanings to symbols, for symbols are meaningful from the very start. So 'let's not imagine the meaning as an occult connection the mind makes between a word and a thing? ${ }^{18}$

Similar objections apply to the suggestion that the soul is the instance which has thoughts. It is inconceivable how an extramundane entity can have facts in the world. Furthermore, there is no reason why some extramundane entity should have them. 'Thoughts think themselves', in the sense that everything that goes on in thinking is completely accounted for by thoughts and what they represent. A soul could only be an inert homunculus, a bystander seeing nothing and doing nothing.

So the hypothesis of the soul or subject seems to be completely superfluous. It does not have any useful property whatsoever beside its simplicity - if that may be called a useful property. With his assumption that the soul is simple, Wittgenstein puts it completely out of action. As William James said in his criticism of the doctrine of Transcendental Egoism: 'The Ego is simply nothing: as ineffectual and windy an abortion as Philosophy can show'. ${ }^{19}$ We might as well discard it - which is what Wittgenstein himself ultimately does in TLP $5.64 \mathrm{ff}$.

7. Why is the soul (subject) said to be simple?

Why did Wittgenstein have such a strong conviction that the soul or subject is, if anything, simple? One superficial answer would be that he was misled by the surface-grammar of language. He thought that the pronoun ' $I$ ' is a name denoting a simple object, the I. It is an indexical name, but no less genuinely name-like for that. A Humean argument shows that the denotation of this name is not in the world (TLP $5.631 \mathrm{ff}$.), and therefore it has to be outside of it,

18. L.J.J. Wittgenstein, Blue Book, pp. 73-74, in The Blue and Brown Books, Oxford, Blackwell, 1958.

19. W. James, The Principles of Psychology, Vol. 1, New York, Henry Holt, 1890, p. 365. Instead of 'Ego', James also uses the terms 'Transcendental Subject' and 'Self'. 
or at least on the boundaries of it. And so he arrives at the strange doctrine of the soul as a chimerical, imaginary object. It has disappeared as an object from the world, but its ghost remains as the 'gaseous' or 'aethereal' denotation of the indexical ' $I$ '. ${ }^{20}$

We think that this answer is too easy. Wittgenstein would not have forgotten his own lessons on the misleadingness of language so quickly. He will certainly have been sensitive to the possibility that ' $I$ ' may be no more a genuine name than ' $A$ ' in ' $A$ thinks $p$ ' and that both names might have to be replaced by long descriptions of complex facts in a completely perspicuous language. After all, he showed such sensitivity in the notes dictated to Moore which we have quoted about $(\$ 4)$. He must have had deeper reasons for his opinion.

We suggest that the answer may be found in the visual metaphor of TLP $5.633 \mathrm{ff}$. Nothing in the visual field suggests that it is seen by an eye. But its contents are such that we may introduce a fictitious 'geometrical eye' from whose standpoint it appears to be seen. ${ }^{21}$ Such an eye does not really exist; it is a fiction similar to the 'point of sight' (also called 'central point' or simply 'eye') which is used in the theory of perspective.

There is a simple relationship between the geometrical eye and the boundaries of its visual field: the latter determine the former, but not conversely. The eye may be seen as the vertex of an imaginary three-dimensional cone containing the things which are seen in the visual field; the surface of this cone is the boundary of the visual field. The boundary of the visual field (including the geometrical eye) does not belong to the field itself; it is unseen and unseeable. It will be clear that each visual cone determines exactly one 'point of sight'. However, the converse does not hold, for a cone starting from a vertex may fan out in various directions.

The I (the subject) is a fiction similar to the geometrical eye. It is the imaginary standpoint (the 'centre of the world', Notebooks 5.8.16) from which reality is experienced. 'Experience as a whole is the field to which the philosophical I stands as does the geometrical eye to the visual field. ${ }^{22}$ As in the case of the geometrical eye, the 'location' of the I is wholly determined by the 'limits' or

20. The latter expressions come from the Blue Book, op. cit., p. 47.

21. The expression 'geometrical eye' comes from the Blue Book, op. cit., pp. 63-64.

22. M.U. Coyne, 'Eye, "I", and Mine: The Self of Wittgenstein's Tractatus", Southern Journal of Philosophy 20, 1982, 313-323, quotation from p. 317. 
'boundaries' of reality (although the converse does not hold): the I is the imaginary entity which precisely experiences this reality. This explains why TLP 5.64 says that 'the I of solipsism shrinks to a point without extension and the reality with which it is correlated remains'.

Just as the surface of the visual cone (including the geometrical eye) does not belong to the visual field which it encompasses, so the limits of reality (including the metaphysical I) do not belong to reality itself. This explains why TLP 5.632 says that 'the subject does not belong to the world; rather, it is a limit of the world'. It would have been more accurate to say that the I does not belong to the world because it is an element of the limit of the world (namely, its 'vertex'), but this seems only a minor lapse. ${ }^{23}$

Now we want to suggest that the essential point which led Wittgenstein to his conception of the simplicity of the soul was his view that such virtual points of view are necessarily simple (pointlike). Thus, he seems not to have thought of such expressions as 'from the point of view (perspective) of the present Government ...', which involve collective viewpoints ascribed to collective entities. He seems to have thought that all perspectives are perspectives from one point. It was this view which made him say in TLP 5.5421 that the I is point-like. (It is merely a virtual thing, but simple, if anything.)

\section{Further evidence for this interpretation}

The picture sketched above is clear and intuitively attractive. However, one might well ask for more arguments and textual evidence. We think that these are not difficult to give.

First, there can be no doubt at all that Wittgenstein regarded the soul or subject as not really existing (virtual); we have already quoted the evidence in $\$ 3$. This also explains why it does not do anything $(\$ 6)$ : it has a purely hypothetical nature.

23. Coyne (op. cit.) has no difficulty with TLP 5.632 because she regards the eye as the limit of the visual field and the I as the limit of reality. We say that the eye and I are only elements of these limits (namely, their vertices). We prefer our own interpretation because we do not see how one can make sense of Coyne's talk about the 'shapes' of the visual field and reality if these shapes are assumed to be bounded by points. How could a point delimit a shape? 
Secondly, the suggestion that Wittgenstein saw the metaphysical subject as the (fictitious) owner of experience becomes very plausible if we regard some of his later writings as reactions to his earlier view. In the Philosophical Remarks in particular, he argued that the perspectival structure of the experienced visual field does not provide one with reasons for postulating a subject as its owner. 'The visual space does not have an owner. . . The representation of visual space is the representation of an object and contains no suggestion of a subject'. ${ }^{24}$ Or as Moore tells us: 'He said that "Just as no eye is involved in seeing, so no Ego is involved in thinking or having toothache", and he quoted, with apparent approval, Lichtenberg's saying "Instead of 'I think' we ought to say 'It thinks" ("it" being used, as he said, as "Es" is used in "Es blitzet"). ${ }^{25}$ Here he came close to the "psychology (philosophy) without a psyche' of Hume and Lichtenberg, in which the I is just a 'grammatical fiction'. He was apparently no longer impressed by Weininger's vehement critique of this view.

Thirdly, the suggestion that Wittgenstein regarded the hypothetical centre of experience as simple because he did not think of perspectives from collective viewpoints, hardly needs textual evidence. The very word 'viewpoint' suggests that this is the most natural way of viewing perspectives. Moreover, similar virtual points occur regularly in the fields of descriptive geometry, projective geometry, geometrical optics, etc., which Wittgenstein must have studied as an engineer, and he may well have had them in mind.

In view of the above three points, our interpretation seems to be backed quite well by textual and general considerations.

In sum, we have come to the conclusion that TLP 5.5421 does not arise from a misunderstanding of language. Rather, it is the result of viewing one's view of reality more geometrico. The pronoun 'I' refers to a geometrical fiction, the I, which is the virtual centre of all experience. Such a centre can only be point-like, never complex, and that is why it is said in TLP 5.5241 that a 'composite soul would no longer be a soul'.

24. L.J.J. Wittgenstein, Philosophical Remarks, ed. by R. Rhees, Oxford, Blackwell, 1964, $\$ 71$.

25. G.E. Moore, 'Wittgenstein's Lectures in 1930-33', in his Philosophical Papers, London, Allen and Unwin, 1959, 252-324, quotation from p. 309. Wittgenstein may have got the Lichtenberg quotation from Weininger, op. cit., part II, ch. 7 . 
Thus, TLP 5.5421 expresses an opinion which is interesting in itself and is closely connected with the remarks on the metaphysical subject in the passages on solipsism. It is illuminated by them and illuminates them in turn. One might even say that these remarks can hardly be understood without taking TLP 5.5421 into account. TLP 5.5421 plays a more prominent role than previous commentators have usually thought.

\section{Why TLP 5.5421 should be rejected}

Nevertheless, it would have been better if TLP 5.5421 had never made its way into the Tractatus.

In the first place, it mars the unity of the work. The soul or subject is totally different from the other entities that populate the treatise. Nowhere else do we encounter virtual entities virtually representing real facts. A consequence of this is that the doctrines of the Tractatus do no apply to it. The picture theory is a good example: it does not explain how virtual representation by pointlike virtual entities might work.

In the second place, the idea of a metaphysical soul or subject distinct from the empirical self is unfortunate in itself. As long as its purely fictitious character is stressed, the idea is innocent enough; but then why introduce it? In geometry and physics, virtual entities may often be very convenient. A good example in mechanics is offered by Hertz's 'invisible masses' (which Wittgenstein referred to in the Notebooks, 6.12.14). These pseudo-objects (Scheingegenstände) enabled him to give a unified account of mechanics. But in philosophy of mind nothing much seems to be gained by introducing the pseudo-object of the metaphysical self. ${ }^{26}$ Moreover, postulating such an entity is a dangerous thing to do. Even if its purely hypothetical character is stressed, it is all too easily imaginable that someone might remark that his mind does not seem

26. A similar critique applies to Dewan's proposal to regard the mind as a virtual governor of the brain of the same type as the virtual governors which are defined over grids of electrical generators. The idea is useful in electrical engineering, but does not have any explanatory value in the philosophy of mind. See E.M. Dewan, 'Consciousness as an Emergent Causal Agent in the Context of Control System Theory', in G.G. Globus, G. Maxwell and I. Savodnik, eds., Consciousness and the Brain: A Scientific and Philosophical Inquiry, New York, Plenum Press, 1976, 181198. 
imaginary to him. And thus it is all too easy to fall prey to illegitimate reifications of the same sort as Schopenhauer's reification of Kant's transcendental unity of apperception. As long as the idea has no obvious value, it is best to avoid it.

In the third place, the introduction of a soul or subject distinct from the empirical self is completely unnecessary within the framework of the Tractatus. Everything which Wittgenstein says about 'my language', 'my world', and the 'truth of solipsism' may just as well, nay, better be said without bringing a separate subject into play. We will devote the remaining part of this paper to a demonstration of how this may be done.

10. The empirical self as the centre of existence

Let us suppose that the pronoun ' $\mathrm{l}$ ' does not refer to an imaginary point, but to a collection of facts; it is an indexical quasi-name of the collection of facts which constitute me. (It is not a genuine name because collections of facts cannot be named.) Thus, we return to Wittgenstein's remark in the notes dictated to Moore that "it is just as impossible that $I$ should be a simple as that "p" should be'. Which consequences does this have?

First, we may easily make sense of the remarks about "my language' and 'my world' in TLP 5.6, as Hintikka pointed out a long time ago. ${ }^{27}$ 'My language' is just another expression for my empirical self, the collection of thoughts I have or may have. (Remember that thoughts are similar to sentences.) Or alternatively, 'my language' may be regarded as the collection of all sentences which express all the thoughts I may have. 'My world' is the collection of all (possible) facts which are represented by the thoughts I may have. At any given time, I may entertain any given subcollection of my collection of possible thoughts, which explains why 'no portion of our experience is a priori' (TLP 5.634). But I cannot transgress the boundaries of what I may think (I cannot have a thought which I cannot have), and therefore 'the limits of my language are the limits of my world' (TLP 5.6) ${ }^{28}$ As $m \gamma$ language is

27. Compare Hintikka, op. cit. (1958).

28. 'Ich kann mir nichts ausser meinem Denken denken; denn dadurch, dass ich es denke, wird es ja mein Denken, und fallt unter die unvermeidliche Gesetze desselben.' ('I can't think anything which goes beyond my thinking; for the very fact 
the language for me, 'the only language which I understand' (TLP 5.62), $m y$ world is the world for me, the only world which I experience (TLP 5.641).

Secondly, we may easily transpose the remarks we made above about the 'perspectival' character of the I to this new setting. The only difference is that the 'viewpoint' from which the world is experienced is no longer simple, but complex. It is a plane or region rather than a point.

It is helpful to consider the case of the visual field again. It may be possible to define a point-like 'geometrical eye' as the point from which the visual field is seen, although this should not be granted too quickly - how should one, for example, account for stereopsis, seeing in depth, if one limits oneself to one point-like geometrical eyc? But even if it were possible to define such an abstract eye, it is more realistic to consider the two eyes taken together, which are both complex in themselves, as the standpoint (region) from which the visual field is seen. The visual field is seen from the collective perspective of a pair of eyes. Wittgenstein seems not to have thought of this possibility, which is, however, completely clear in itself.

According to us, the case of the ' $\mathrm{I}$ ', 'soul' or 'self' is analogous. These entities, too, may perhaps be defined as simple virtual points of perspective, but it is more realistic to regard them as collections of various real elements (thoughts), each of them complex in itselfthat is, to identify them with the empirical self. We may grant that 'the I enters into philosophy because "the world is my world"', as Wittgenstein writes in TLP 5.641. However, that does not tell us anything about the nature of the I. In particular, it does not tell us that it is simple. The I may be as complex as the eyes jointly are.

Thirdly, it is easy to do justice to the remarks about the nonencounterability of the self. The empirical self is a collection of facts, all of them belonging to the world. It is, in principle, possible that this self may encounter itself in the world, in the sense that it could contain a picture of every fact of which it is composed. It even does not have to be infinite to be capable of this feat, as Hacker wrongly supposes. ${ }^{29}$ For we could envisage circles of representation in

that I am thinking it turns it into my thinking, and makes it fall under the inevitable laws of thinking.') Wittgenstein? No, J.G. Fichte, Die Bestimmung des Menschen, Berlin, Voss, 1800, p. 157.

29. Hacker, op. cit., pp. 77-78. 
the sense that a picture of a picture of a fact (or a picture to the $n$-th degree of a fact) might be identical with this fact itself. In this way, there could be a picture of every picture, while the total collection of pictures would yet remain finite.

However, even if the empirical self contained a picture of every picture of which it consists, this would not guarantee that the empirical self is able to recognise the facts of which it is composed as bcing elements of itself. For as we saw above in our remarks about the impossibility of formulating psychophysical laws, it is impossible to represent, say or think what facts represent. Even if the self saw itself completely (for example, if it were identical with the brain and observed itself in action with the celebrated 'autocerebroscope'), it would not be able to recognise itself as itself, because it could never see, say or think that the facts which it observes represent exactly the same facts which it is representing itself. Therefore the empirical self is in a sense 'invisible' or 'unknowable' to itself, even if it saw and knew itself completely.

Fourthly, our account has the (minor) advantage over the view of the self as the purely imaginary centre of all experience that it does not exclude the possibility that two minds might have exactly the same contents. Two different collections of pictures might represent exactly the same facts, whereas minds which are completely determined by their experiences can only be different if they have at least one different experience.

\section{Living with the empirical self}

In short, all the things which Wittgenstcin says about the metaphysical self may just as well be said about the empirical self. It seems wise to use Occam's razor and excise the metaphysical self from the Tractatus.

This does not imply that everything which Wittgenstein says about the empirical self is unobjectionable. For example, the idea that thoughts are of a linguistic nature seems to be an unfortunate relapse to the mediaeval doctrine of a 'language of thought' or its short revival in German Idealism (Humboldt, Schelling, Hegel, Herder). Hegel ${ }^{30}$ boldly asserted that 'we think in nouns', and it is

30. Quoted without reference by J. Hadamard, The Psychology of Invention in the Mathematical Field, 2nd ed., Princeton, N.J., Princeton U.P., 1949, p. 68. 
not unfair to suggest that Wittgenstein came rather close to this view, which was repudiated by almost all major philosophers who came before and after him. ${ }^{31}$

Wittgenstein seems to have been led to it because he only had a representational theory of sentences. (His picture-theory of sentences might better be called a sentence-theory of pictures.) $\mathrm{He}$ derived this theory from Hertz's theory of 'dynamical models'; the only modification which he made was to give a linguistic (semantical) twist to it. ${ }^{32} \mathrm{With}$ hindsight, this linguistic twist seems regrettable. Hertz's notion of models (including his account of dynamical mental models) is still applicable to modern psychological models of mental representation such as the 'Boltzmann machine', while a theory of mental sentences is hopelessly out of date here. ${ }^{33}$

But whatever the defects of the theory of the empirical self, these may be amended, for this notion seems to have a good deal of substance. With the metaphysical self it is different, and therefore we had better forget about TLP 5.5421 and the passages related to it. The simple metaphysical self is dead, but the complex empirical self is alive and well: l'âme est morte, vive l'âme.

Dept. of Philosophy,

Erasmus University P.O. Box 1738, 3000 DR, Rotterdam,

The Netherlands.

31. I am ignoring the philosophers which have proclaimed themselves to be the philosophers of modern cognitive science (Fodor, Pylyshyn and the like). First, cognitive scientists themselves are usually bewildered by the claims these philosophers make on their behalf, and secondly, this kind of philosophy is rapidly dying out anyway (cf. note 33).

32. A good account of Hertz's influence on the picture-theory may be found in J. Griffin, Wittgenstein's Logical Atomism, Oxford, Oxford U.P., 1964.

33. The 'Boltzmann machine' is a device composed of simple elements analogous to neurons whose collective behaviour is described by the laws of statistical mechanics. It is able to make 'dynamical internal models' of the statistical structure of its environment which exactly conform to the definition $\mathrm{H}$. Hertz gave of such models in his Die Prinzipien der Mechanik in neuem Zusammenhange dargestellt, Leipzig, Barth, 1894. See, e.g., D.H. Ackley, G.E. Hinton and T.J. Sejnowski, 'A Learning Algorithm for Boltzmann machines', Cognitive Science 9, 1985, 147169, repr. in J.A. Anderson and E. Rosenfeld (eds.), Neurocomputing: Foundations of Research, Cambridge, Mass., MIT Press, 1988, 638-649. This anthology contains many more examples of non-sentential psychological models of a 'Hertzian' kind. 